\title{
A comprehensive study of the changes in ecdysteroid levels during the feeding phase of fifth instar larvae of the silkworm, Bombyx mori (Lepidoptera: Bombycidae)
}

\author{
Bela KESHAN, Bembem THOUNAOJAM and Sanathoibi D. KH \\ Department of Zoology, North-Eastern Hill University, Shillong-793022, Meghalaya, India; e-mails: bkeshan@hotmail.com; \\ bemthounaojam@gmail.com; ktgitanjali2@gmail.com
}

Key words. Lepidoptera, Bombycidae, Bombyx mori, ecdysteroid, insulin, juvenile hormone, food deprivation, critical weight

\begin{abstract}
The present study describes changes in haemolymph ecdysteroid levels during the feeding phase of fifth instar larvae of Bombyx mori. A small and sharp peak in ecdysteroid level was recorded on day 4 when larvae had already reached the critical weight $(2.76 \pm 0.11 \mathrm{~g})$ for metamorphosis. Food deprivation of larvae from day 4 resulted in an increase in the ecdysteroid level. Injection of insulin in both 1 day (before reaching critical weight) and 4 day (after reaching critical weight) old fed larvae resulted in an increase in the ecdysteroid level. However, when deprived of food only the haemolymph ecdysteroid levels of 4 day old larvae respond to an injection of insulin. The hormone level was also increased by treating 1day old larvae with a juvenile hormone analogue, but again, like insulin, only the fed larvae were affected by this treatment. Neck- and thorax-ligated 4 day old larvae had decreased ecdysteroid levels compared to both fed and food deprived larvae. However, a significant increase in ecdysteroid level was recorded in both neck- and thorax-ligated larvae injected with insulin. The injection of 20-hydroxyecdysone into 4 day old larvae resulted in an increase in the level of this substance in the haemolymph of fed and food deprived larvae, but the level was significantly higher in neck- and thoraxligated larvae. The data, thus, indicates that ecdysteroid levels vary both in relation to the critical weight of the larvae and its nutritional status, and insulin might also play an important role in regulating the level of ecdysteroid.
\end{abstract}

\section{INTRODUCTION}

The growth and development of an insect is under the control of various intrinsic and extrinsic factors such as hormones and nutrition (Riddiford, 1994; Nijhout, 2003; Riddiford et al., 2003; Dubrovsky, 2005; Mirth \& Riddiford, 2007; Truman \& Riddiford, 2007; Layalle et al., 2008; Nijhout et al., 2014). The classical idea is that the synthesis and release of the insect steroid hormone, ecdysteroid, by the prothoracic gland (PTG), are governed by the prothoracicotropic hormone (PTTH), a neuropeptide produced by the neurosecretory cells (NSCs) in the brain (Bollenbacher \& Granger, 1985; Gilbert et al., 2002; Rybczynski, 2005; Truman, 2006; Marchal et al., 2010). However, in recent years, it has been shown that in Bombyx mori, the ecdysteroid synthesis in the PTG is also controlled by nervous connections and other neuropeptides, such as prothoracicostatic peptide and bommomyosuppresin (Yamanaka et al., 2005; Tanaka, 2011). In Drosophila melanogaster, serotonergic neurons respond to nutrients and regulate the biosynthesis of ecdysteroid (Shimada-Niwa \& Niwa, 2014). The ecdysteroidogenesis in the PTG is also stimulated by an unidentified autocrine factor, as recorded in B. mori $(\mathrm{Gu}$, 2007). A study on the stimulation of ecdysteroidogenesis by bombyxin and bovine insulin ( $\mathrm{Gu}$ et al., 2009, 2015) indicates that insulin-like peptides also regulate ecdysteroidogenesis. The stimulation of ecdysteroidogenesis in the PTG by insulin/insulin-like growth peptides/insulin signaling is also reported in other insects, such as Rhodnius prolixus and D. melanogaster (Vafopoulou \& Steel, 1997; Caldwell et al., 2005; Colombani et al., 2005; Mirth et al.,
2005). The gut tissues are also a source of ecdysiotropic peptides (see review by Marchal et al., 2010).

Nutritional status of an insect can influence the synthesis and release of PTTH by the NSCs in the brain and/or cause deficiency in PTTH signal transduction, which in turn alters the rate of ecdysteroid synthesis by the PTG (Chen \& $\mathrm{Gu}, 2006)$. Juvenile hormone ( $\mathrm{JH})$ modulates the competency of the PTG to PTTH during the early phase of the last larval instar in B. mori (Gu et al., 1997). Although PTG is the main source of ecdysteroid synthesis, tissues such as ovaries, testis, epidermis and oenocytes are also thought to synthesize ecdysteroids in many insects (Ohnishi \& Chatani, 1977; Gelman et al., 1989; Jenkins et al., 1992; Jarvis et al., 1994; Gillott \& Ismail, 1995; Telang et al., 2007; Marchal et al., 2010; Hentze et al., 2013). The stimulation of ecdysteroidogenesis by bovine insulin in tissues such as the ovary is also reported in Aedes aegypti and Phormia regina (Graf et al., 1997; Riehle \& Brown, 1999; Maniere et al., 2004).

Nutritional level determines the time it takes to reach the critical or final body size in insects. Once body size reaches this threshold, it leads to a cascade of endocrine events, which initiate metamorphosis (Nijhout \& Williams, 1974a), even though the maximum final body size may not be attained by the larvae. In other words, last instar larvae after attaining the critical weight undergo successful metamorphosis, even when subsequently deprived of food. The interaction between $\mathrm{JH}$ and ecdysteroids is known to regulate insect growth in relation to its state of nutrition. In addition, the insulin/IIS signaling pathway also regulates 
insect growth. Much of the understanding of the critical weight and its correlation with PTTH, ecdysteroid and insulin/IIS signaling pathway has emerged from studies on D. melanogaster and Manduca sexta (Nijhout \& Williams, 1974a; Mirth et al., 2005; Shingleton et al., 2005; Mirth \& Riddiford, 2007; Layalle et al., 2008; Stieper et al., 2008; Mirth \& Shingleton, 2012; Koyama et al., 2014). The central idea is that when a larva reaches the critical weight, JH secretion stops and PTTH is released, which triggers the PTG to secrete ecdysone for metamorphosis (Nijhout, 2003). However, the integration of JH with other factors in regulating insect growth is not very clear. A recent study by Mirth et al. (2014) reveals an intimate link between JH, ecdysteroid and the insulin signaling pathway, whereby $\mathrm{JH}$ controls body size by regulating ecdysone synthesis.

The present study is thus an attempt to demonstrate that changes in haemolymph ecdysteroid levels during the feeding phase of fifth instar larvae of $B$. mori are in some way associated with the attainment of the critical weight both in fed and food deprived conditions. The changes in ecdysteroid levels that occurred when insulin was exogenously applied under different feeding conditions in association with the attainment of the critical weight by fifth instar larvae were also recorded. Ecdysteroid titer was also measured in the haemolymph of methoprene-treated larvae as it is suggested that $\mathrm{JH}$ regulates insect growth via ecdysone and the insulin signaling pathway, whereby $\mathrm{JH}$ controls body size by regulating ecdysone synthesis (Mirth et al., 2014). In addition, ligation experiments were performed to throw some light on the involvement of some other tissues other than PTG in insulin-mediated ecdysteroidogenesis and to explain the attainment of the critical period by fifth instar larvae of Bombyx. This study indicates that in B. mori, the ecdysteroid levels fluctuate under both fed and food deprived conditions during the fifth larval instar and in relation to the critical weight of the larvae, and that both $\mathrm{JH}$ and insulin play a role in regulating the ecdysteroid level.

\section{MATERIAL AND METHODS}

\section{Experimental insect}

A bivoltine, sex-limited strain of silkworm (Bombyx mori) L. (CSR 18, BB1-0293) was used in the present study. Diseasefree layings (dfls) of silkworms were obtained from the Central Sericultural Germplasm Resource Centre (CSGRC), Central Silk Board, Hosur, Tamil Nadu and reared on fresh mulberry leaves in the laboratory under controlled conditions (temperature, $25 \pm$ $1{ }^{\circ} \mathrm{C}$; humidity, 60-90\%, photoperiod, 12L: 12D).

\section{Measurement of larval body weight, design of starvation experiments and determination of the critical weight}

Larval body weight of un-anaesthetized larvae was determined using a digital balance (Make-Sartorious, Model No. B223S) and weighing all the larvae during the beginning of photophase over a period of $1-2 \mathrm{~h}$. The sensitivity of the balance was $0.001 \mathrm{~g}$ or $1 \mathrm{mg}$.

The synchronously developing fifth instar larvae were deprived of food at various times and the control group of larvae of similar weight reared at the same time were fed ad libitum. To prevent starved larvae from desiccating, the room humidity was maintained at a high level and a water source was also kept near the rearing trays. Larvae were inspected every $6 \mathrm{~h}$ during the photo- phase (day), with $12 \mathrm{~h}$ interval during the scotophase (night), for pupation and for wandering and spinning behaviour. Only female larvae were included in the experiments in order to avoid any sex specific variations in the data. Age during fifth (last) larval instar was measured in terms of days after ecdysis. The first day of feeding of fifth instar larvae after ecdysis was designated as day 0 .

To determine the critical weight, breakpoint analysis was used as described previously (Stieper et al., 2008; Mirth et al., 2014). A breakpoint analysis exploits the fact that the relationship between larval weight when starved and time to pupation changes after critical weight, and this change can be identified by using a bi-segmental linear regression (Mirth et al., 2014). In the present study, the inflection in the regression line was obtained using R software (www.r-project.org) (Ihaka \& Gentleman, 1996). Davies' statistical test was used to determine the significance of the inflection. Growth rate of fifth instar larvae in relation to the critical weight was modelled as two exponential periods of growth, one before and one after the attainment of the critical weight. The analysis of two phases of the growth curve was done using best-fitting equations following Nijhout et al. (2006).

\section{Surgical procedures}

The larvae were anaesthetized with diethyl ether before ligation. Neck ligation was performed by ligating the larvae between the head and the prothorax, and for thorax ligation, the cotton thread was tied tightly between the metathoracic region and the first abdominal segment. After the removal of the anterior part, the wounded surface was sealed with melted paraffin wax.

\section{Hormonal treatment}

Methoprene, a juvenile hormone analogue (JHA), was applied topically in acetone at a concentration of $2 \mu \mathrm{g} /$ larva in a total volume of $5 \mu \mathrm{l}$ along the dorsal vessel of fifth instar larvae. Bovine insulin was dissolved in $10 \mathrm{mM} \mathrm{HCl}$ and a stock solution of 20-hydroxyecdysone (20E) in absolute ethanol was also prepared. Both insulin and $20 \mathrm{E}$ were diluted by adding insect ringer solution and then injected into larvae at a concentration of $2 \mu \mathrm{g} /$ larva in a total volume of $5 \mu \mathrm{l}$ via the second abdominal leg using a Hamilton syringe. A control group was also similarly injected but only with insect ringer solution. All hormones were obtained from Sigma-Aldrich and all larvae were anaesthetized before injection with hormone.

\section{Measurement of the level of ecdysteroid in haemolymph using an enzyme-immunoassay}

The ecdysteroid level in the haemolymph was measured using enzyme-immunoassay (EIA) as described by Porcheron et al. (1989). Haemolymph was collected from larvae via an incision in their proleg then mixed with methanol (1:9) before centrifugation at $10,000 \times \mathrm{g}$ for $10 \mathrm{~min}$. The resulting supernatant was then evaporated to dryness in a vacuum and resuspended in EIA buffer. For the early fifth instar larvae, $100 \mu \mathrm{l}$ of haemolymph, after extraction and evaporation, was resuspended in only $50 \mu 1$ of EIA buffer to improve the sensitivity of measuring ecdysteroid at levels above the detectable range. EIA buffer, 20E antiserum, $20 \mathrm{E}$ acetylcholineesterase (AChE) tracer and Ellman's reagent were purchased from Cayman Chemical Company, USA. The assay was calibrated using $20 \mathrm{E}$ as the standard, which was obtained from Sigma-Aldrich. The calibration curve was drawn by plotting different concentrations of $20 \mathrm{E}$ (ranging from $10 \mathrm{ng} / \mathrm{ml}$ to $0.1562 \mathrm{ng} / \mathrm{ml})$ versus the logit $\left(\mathrm{B} / \mathrm{B}_{0}\right)$ values using Cayman EIA software. The assay was done in a total volume of $150 \mu 1$, composed of $50 \mu \mathrm{l}$ of $20 \mathrm{E}$ standard, $50 \mu \mathrm{l}$ of $20 \mathrm{E} \mathrm{AChE}$ tracer and $50 \mu 1$ of 20E EIA antiserum. Ellman's reagent was used for the chromogenic reaction and absorbance was read at $405 \mathrm{~nm}$. Under these conditions, the limits to the detection of ecdysteroid was 


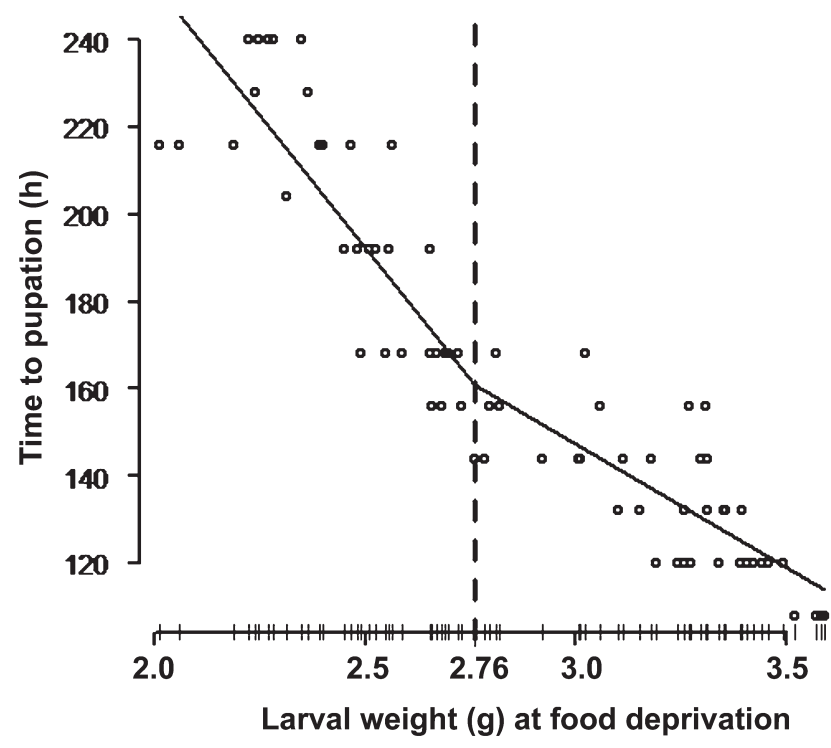

Fig. 1. Time to pupation of fifth instar larvae of Bombyx deprived of food when they attained different weights. The inflection in regression line indicates the point at which larvae reached the critical weight as determined by a breakpoint analysis of a bi-segmental regression line using software R (Davies' test, $\mathrm{p}<$ 0.005).

$7.8 \mathrm{pg} /$ well to $500 \mathrm{pg} /$ well for the 96 -well microtiter plate, used in the EIA assay system. The concentration was calculated using Cayman EIA software and the data expressed as Mean \pm SEM of 5-7 separate determinations.

\section{Statistical analysis}

Student's t-test was used in the analysis of the data and the results presented as mean \pm SEM. A general linear model and analysis of variance (ANOVA) followed by a Bonferroni Multiple test was used to analyze some of the experimental data.

\section{RESULTS}

\section{Critical weight and measurement of ecdysteroid levels in the haemolymph}

In our laboratory fifth instar larvae feed for 7 days before entering the wandering phase. As the weight of final instar larvae determines when they pupate the critical weight for pupation was studied by starving final instar larvae after reaching certain weights. This revealed that when fifth instar larvae were deprived of food from day 1 they all died within 5-6 days. When larvae were deprived of food, beginning from day 3 , more than $50 \%$ of them died, but the rest survived and pupated. When food deprivation started from day 4, most of the larvae survived and pupated, but almost one day earlier than larvae not deprived of food. Since the starved Bombyx larvae pupated earlier to those that were not starved, a breakpoint analysis using a bi-segmental linear regression was used to determine the critical weight following the method of Stieper et al. (2008). The breakpoint (critical weight) was $2.76 \mathrm{~g}$ (95\% CI: 2.65-2.87 g) when the larval weight at the time they were deprived of food was plotted against time of pupation (Fig. $1)$. Based on Davies' test a significant change $(p<0.005)$ in slope occurred at this breakpoint.

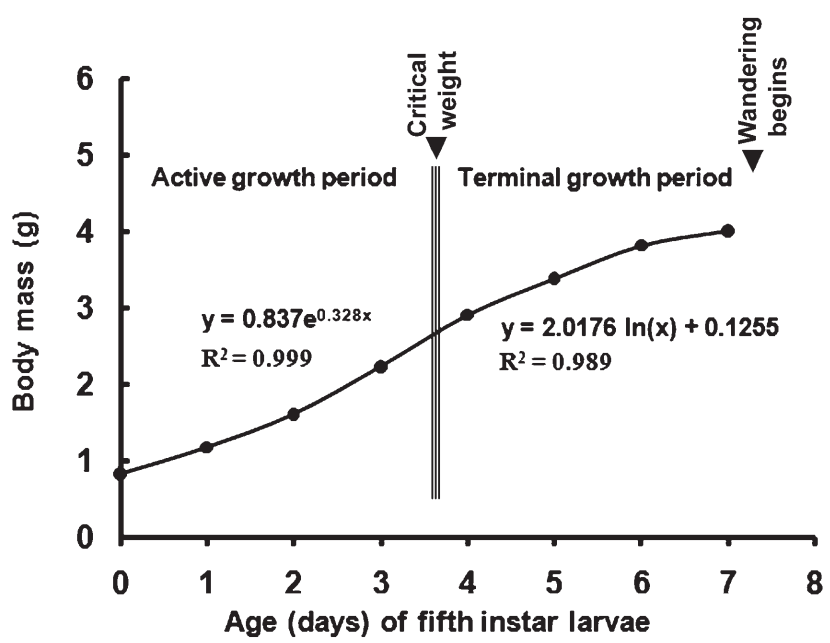

Fig. 2. Growth curve of fifth instar larvae of the silkworm, $B$. mori, showing the active growth period (AGP), terminal growth period (TGP) and a critical weight of $2.76 \mathrm{~g}$. The AGP curve (before the critical weight is attained) is concave upwards and TGP (after the critical weight is attained) is concave downwards. The best-fitting equations for both AGP and TGP are indicated. Each point is the mean of more than 40 larvae and standard errors not shown as less than the size of data points.

During the last instar the average body weight of larvae that were provided with food increased from $0.832 \pm 0.003$ $\mathrm{g}$ on day 0 to $4.0 \pm 0.05 \mathrm{~g}$ on day 7 (Fig. 2). Analysis of growth curve of larvae (Fig. 2) revealed that fifth instar larvae reached the critical weight $(2.76 \pm 0.11 \mathrm{~g})$ between 3.5 and 4 days. Since the body growth of an insect is not constant throughout its development and attaining the critical weight initiates the cessation of growth and onset of meta-

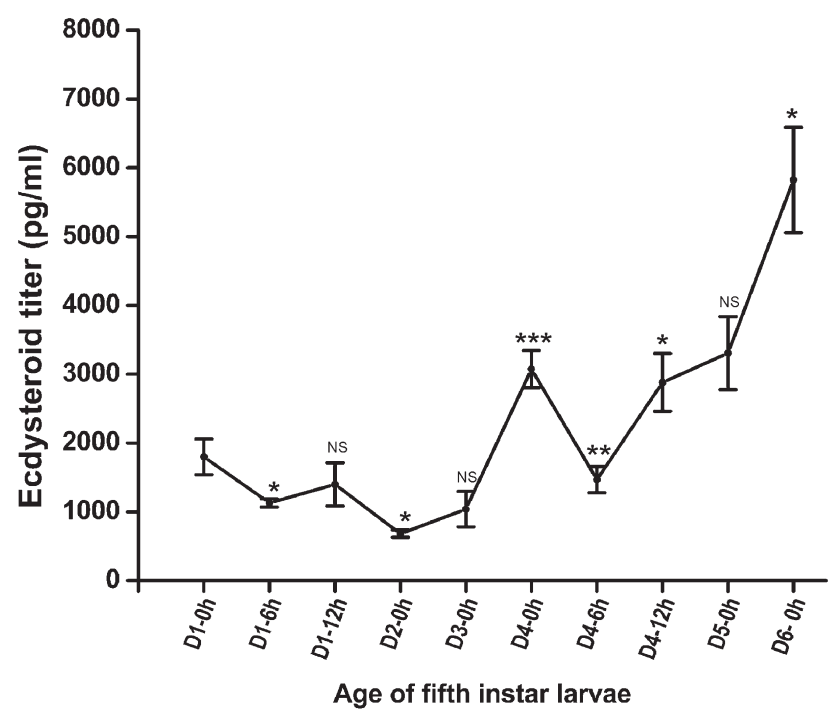

Fig. 3. Change in the level of ecdysteroid in the haemolymph of fifth instar larvae of the silkworm, B. mori, recorded during their feeding phase. Each point is a mean value of 5-7 separate determinations and the error bars are the standard error of mean (SEM). The labels on $\mathrm{X}$-axis are not to scale. The significance of the differences between adjacent means were tested using Student's t-test. The asterisks indicate that adjacent means differ significantly $\left(* \mathrm{p}<0.05,{ }^{* *} \mathrm{p}<0.01,{ }^{* * *} \mathrm{p}<0.001\right)$. NS - not significant at $\mathrm{p}<0.05$. 
A

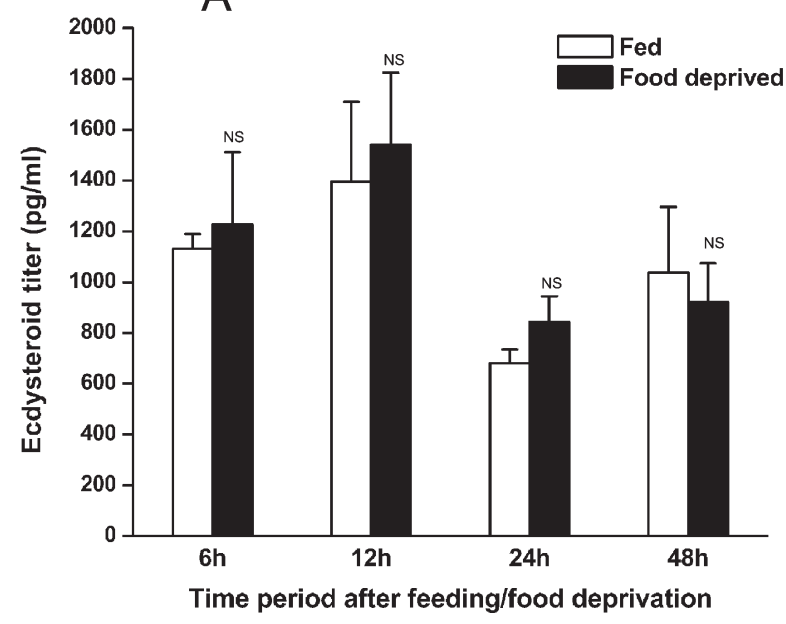

B

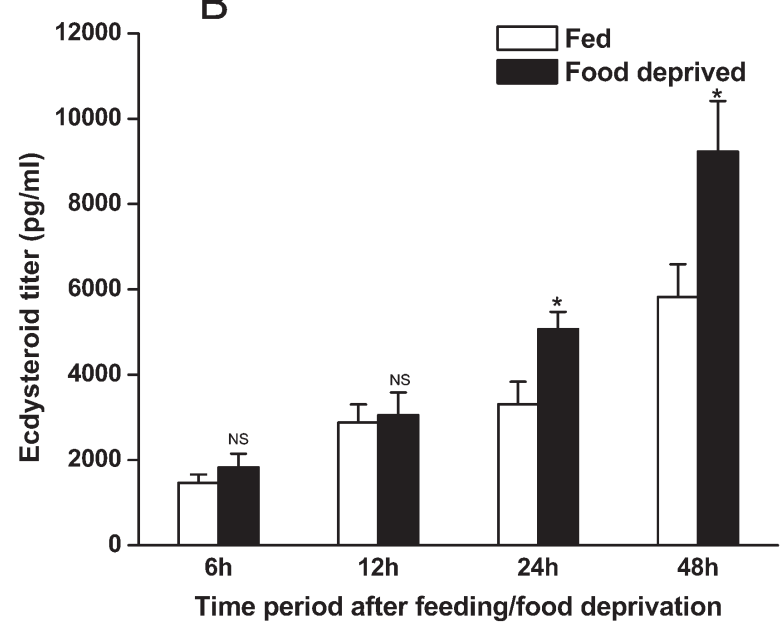

Fig. 4. Effect of food deprivation on the level of ecdysteroid in the haemolymph of fifth instar larvae of the silkworm, B. mori. A food deprivation from day 1 ; B - food deprivation from day 4. Each column is the mean of 5-7 separate determinations and the error bars are standard errors of the means (SEM). The asterisks $\left(^{*}\right)$ indicate that the result differs significantly from that recorded for control (fed) larvae $(\mathrm{p}<0.05)$. NS - not significant at $\mathrm{p}<0.05$.

morphosis, the present study made an attempt to determine silkworm larval growth in relation to its critical weight. This revealed that larval growth is exponential both before and after the critical weight is achieved, but less so after the larvae reach the critical weight.

Although food deprivation, beginning on day 4, did not result in the abnormal development of pupae, it did result in a significant decrease in the weight of the cocoon, pupal weight and pupal duration. The pupal and cocoon weights of larvae deprived of food beginning on day 4 were 0.968 $\pm 0.02 \mathrm{~g}$ and $0.89 \pm 0.004 \mathrm{~g}$, respectively, which is $57 \%$ and $25 \%$ of the values recorded for the control group. Pupal duration was shortened by almost 1 day by depriving the larvae of food from day 4 onwards during the final larval instar.

In fed larvae, on day 1 of the last larval instar, the ecdysteroid level was $1798 \pm 259 \mathrm{pg} / \mathrm{ml}$, and after $6 \mathrm{~h}$ of feeding, the hormone level decreased to $1130 \pm 61 \mathrm{pg} / \mathrm{ml}$ (Fig. 3). On day 2 of the fifth larval instar, the hormone level further decreased to $681 \pm 54 \mathrm{pg} / \mathrm{ml}$. The first sharp and significant increase in hormone level was recorded on day 4 (3074 \pm $270 \mathrm{pg} / \mathrm{ml})$, when larvae reached the critical weight $(2.76$ $\pm 0.11 \mathrm{~g}$ ) for metamorphosis. After $6 \mathrm{~h}$ of feeding on day 4 , the hormone level decreased to $1467 \pm 192 \mathrm{pg} / \mathrm{ml}$, but after $12 \mathrm{~h}$ of feeding the level significantly increased to $2880 \pm$ $420 \mathrm{pg} / \mathrm{ml}$. On day 6 , the level further increased to $5824 \pm$ $766 \mathrm{pg} / \mathrm{ml}$ of haemolymph (Fig. 3).

\section{Changes in the level of ecdysteroid in the haemolymph of fed and food deprived larvae}

The hemolymph ecdysteroid levels of larvae deprived of food for different periods of time from day 1 (i.e., before attaining the critical weight) and day 4 (after attaining the critical weight) were determined. This revealed that food deprivation of 1 day old larvae did not result in a difference in ecdysteroid levels of larvae deprived of food for 6 h, $12 \mathrm{~h}, 24 \mathrm{~h}$ and $48 \mathrm{~h}$, compared with that of the control groups (Fig. 4A). However, food deprivation of 4 day old larvae caused a significant increase in the ecdysteroid level of those deprived of food for $24 \mathrm{~h}$ and $48 \mathrm{~h}$ (Fig. 4B). After being deprived of food for $24 \mathrm{~h}$ the ecdysteroid level was $5067 \pm 406 \mathrm{pg} / \mathrm{ml}$ and after $48 \mathrm{~h}$ the level was $9230 \pm 1185$ $\mathrm{pg} / \mathrm{ml}$, which are significantly greater than the $3305 \pm 530$ $\mathrm{pg} / \mathrm{ml}$ and $5824 \pm 766 \mathrm{pg} / \mathrm{ml}$, recorded for the controls, respectively.

\section{Changes in hemolymph ecdysteroid levels in neck- and thorax-ligated larvae}

The ecdysteroid levels were measured $24 \mathrm{~h}$ after neckor thorax-ligation of 4 day old fifth instar larvae, at which time they had reached the critical weight for metamorphosis. The data (Fig. 5) reveal that the hemolymph ecdysteroid levels were significantly less in neck- and thorax-ligat-

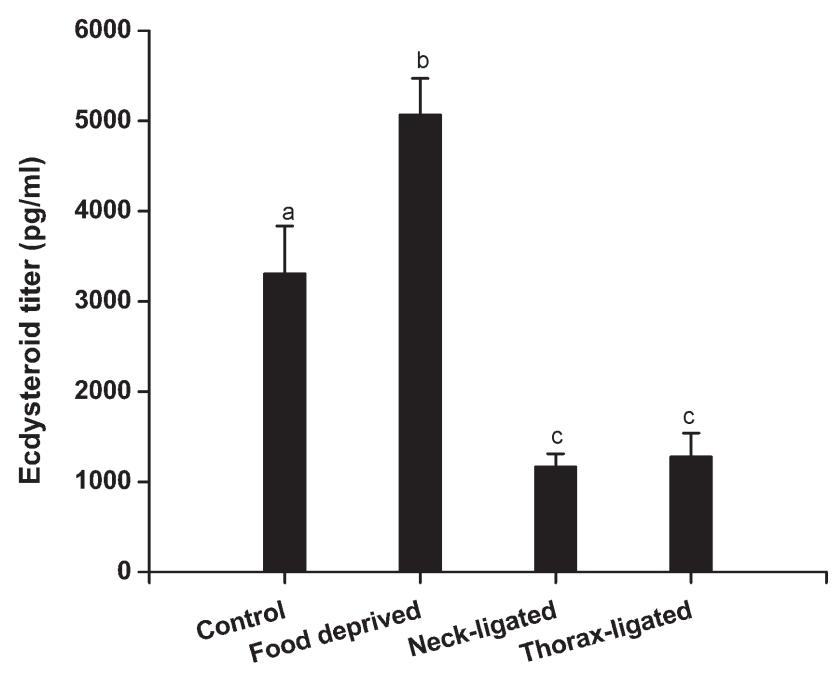

Fig. 5. Change in level of ecdysteroid in the haemolymph of neck- and thorax-ligated fifth instar larvae of the silkworm, $B$. mori. Individuals were ligated on day 4 and the hormone level determined $24 \mathrm{~h}$ later. Each column is the mean of 5-7 separate determinations and the error bars are the standard errors of the means (SEM). Treatments with different letters differ significantly at $\mathrm{p}<0.05$. 

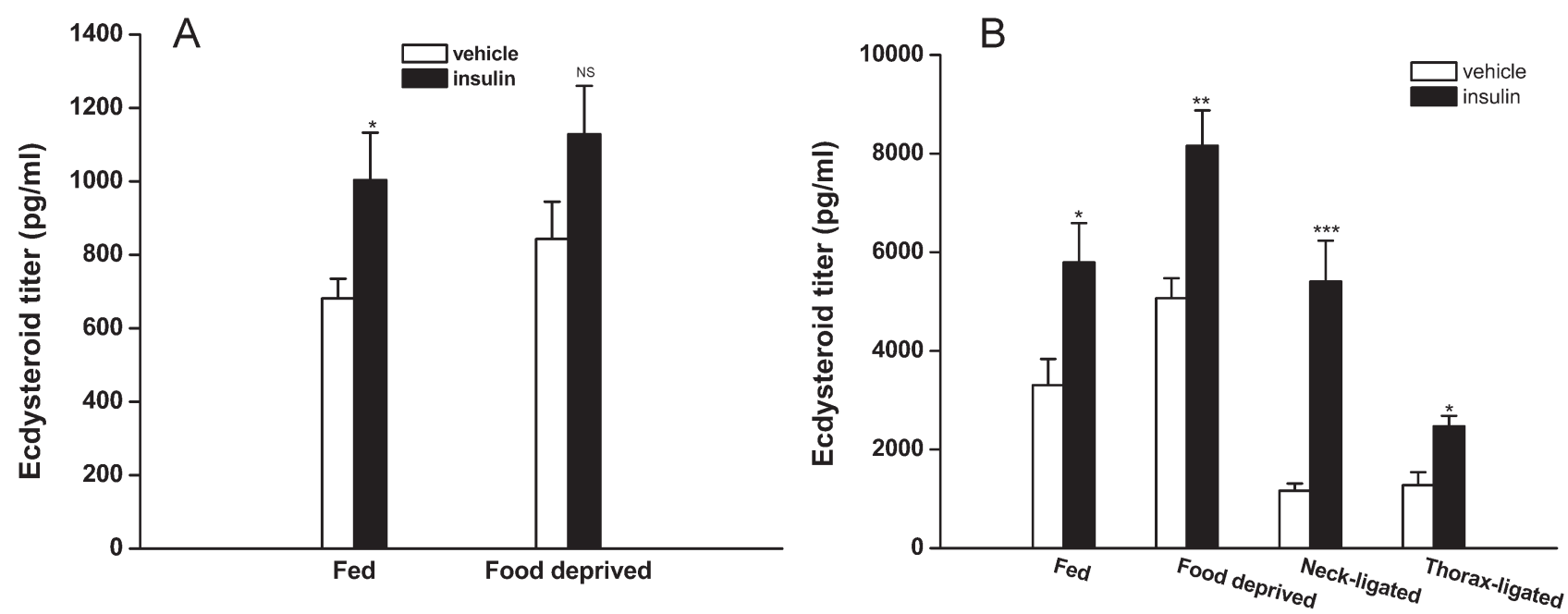

Fig. 6. Effect of injecting insulin on level of ecdysteroid in the haemolymph. Graph shows the hormone level $24 \mathrm{~h}$ after the injection of fifth instar larvae. A - food deprivation from day 1; B - food deprivation and ligation from day 4. Each column is the mean of 5-7 separate determinations and the error bars are the standard errors of the means (SEM). The asterisks indicate those that differ significantly from that recorded for the control (vehicle-treated) larvae $\left({ }^{*} \mathrm{p}<0.05,{ }^{* *} \mathrm{p}<0.01,{ }^{* * *} \mathrm{p}<0.001\right)$. NS - not significant at $\mathrm{p}<0.05$.

ed larvae (1164 \pm 146 and $1276 \pm 265 \mathrm{pg} / \mathrm{ml}$, respectively) than in fed and food deprived larvae.

\section{Effect of insulin on haemolymph ecdysteroid levels}

Day 1 and day 4 fifth instar larvae were injected with a dose of $2 \mu \mathrm{g} /$ larva of insulin and after $24 \mathrm{~h}$ their ecdysteroid levels were measured. The data (Figs 6A, B) indicates that the insulin caused a significant increase in haemolymph ecdysteroid levels of both 1 day and 4 day old larvae, fed ad libitum. In 1 day old fed larvae, the insulin caused an increase in the ecdysteroid level from $681 \pm 54 \mathrm{pg} / \mathrm{ml}$ to $1004 \pm 129 \mathrm{pg} / \mathrm{ml}$, whereas, in 4 day old larvae, the ecdysteroid level increased to $5793 \pm 796 \mathrm{pg} / \mathrm{ml}$ from $3305 \pm$ $530 \mathrm{pg} / \mathrm{ml}$.

The injection of insulin into larvae deprived of food resulted in an increase in ecdysteroid levels, but only in 4 day old larvae, not 1 day old larvae (Figs 6A, B). The ecdysteroid level in 4 day old larvae injected with insulin and deprived of food increased to $8162 \pm 713 \mathrm{pg} / \mathrm{ml}$ from $5067 \pm 406 \mathrm{pg} / \mathrm{ml}$, recorded for the food deprived larvae. The inducing effect of insulin on ecdysteroidogenesis was also recorded in neck-ligated larvae in which the ecdysteroid level increased to $5408 \pm 828 \mathrm{pg} / \mathrm{ml}$ (Fig. 6B). Surprisingly, the injection of insulin also caused an increase in ecdysteroid level in thorax-ligated larvae, which were no longer being controlled by their prothoracic glands. However, the magnitude of the increase in ecdysteroid level in thorax-ligated larvae was less than that recorded for neckligated larvae (Fig. 6B).

\section{Effect of methoprene and 20E treatment on haemolymph ecdysteroid level}

The topical application of methoprene at a dose of $2 \mu \mathrm{g} /$ larva into 1 day old fed larvae resulted in an increase in ecdysteroid level from $681 \pm 54 \mathrm{pg} / \mathrm{ml}$ to $1081 \pm 126 \mathrm{pg} /$ $\mathrm{ml}$, measured $24 \mathrm{~h}$ after the topical application (Fig. 7). However, in food deprived larvae, this treatment did not result in an increase in the ecdysteroid level.
The injection of $20 \mathrm{E}$ at a dose of $2 \mu \mathrm{g} /$ larva into 4 day old larvae, as expected, resulted in an increase in ecdysteroid level under all experimental conditions, compared with the control larvae (Fig. 8). The data showed that among the 20E-treated fed and food deprived larvae, no significant differences in ecdysteroid levels were recorded. In 20E-treated neck-ligated larvae, however, higher levels of ecdysteroid were recorded in their haemolymph $(124 \pm 22 \mathrm{ng} / \mathrm{ml})$ than in that of both 20E-treated fed and food deprived larvae (17-22 ng/ml). The injection of $20 \mathrm{E}$ into thorax-ligated larvae also resulted in higher levels of ecdysteroid $(60 \pm 7 \mathrm{ng} / \mathrm{ml})$ than recorded for 20E-treated fed and food deprived larvae, but the level was less than that recorded for 20E-treated neck-ligated larvae.

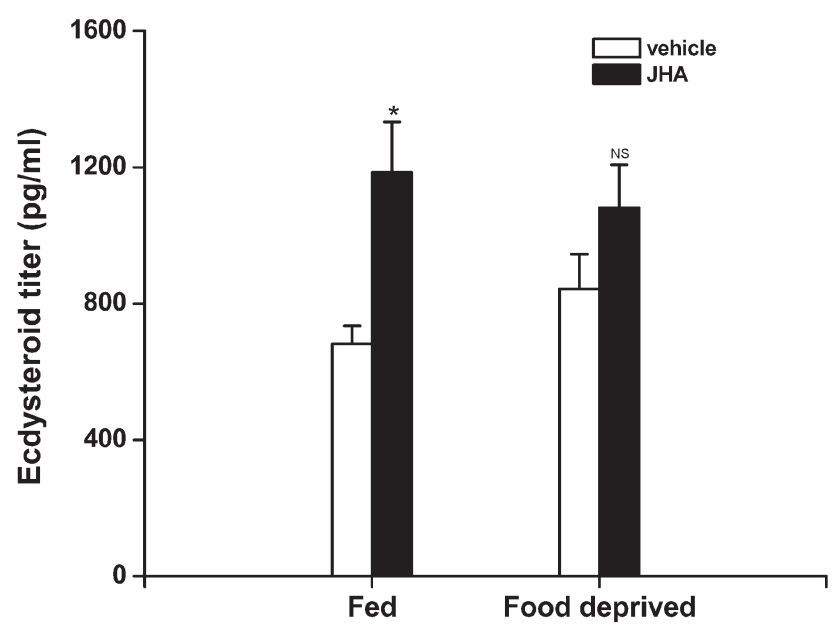

Fig. 7. Effect of topical application of methoprene (JHA) on the level of ecdysteroid in the haemolymph. Graph shows the level of the hormone $24 \mathrm{~h}$ after the topical application of fed and food deprived larvae on day 1 . Each column is the mean of 5-7 separate determinations and the error bars are the standard errors of the means (SEM). The asterisks $(*)$ indicate those that differ significantly from that recorded for the control (vehicle-treated) larvae $(\mathrm{p}<0.01)$. NS - not significant at $\mathrm{p}<0.05$. 


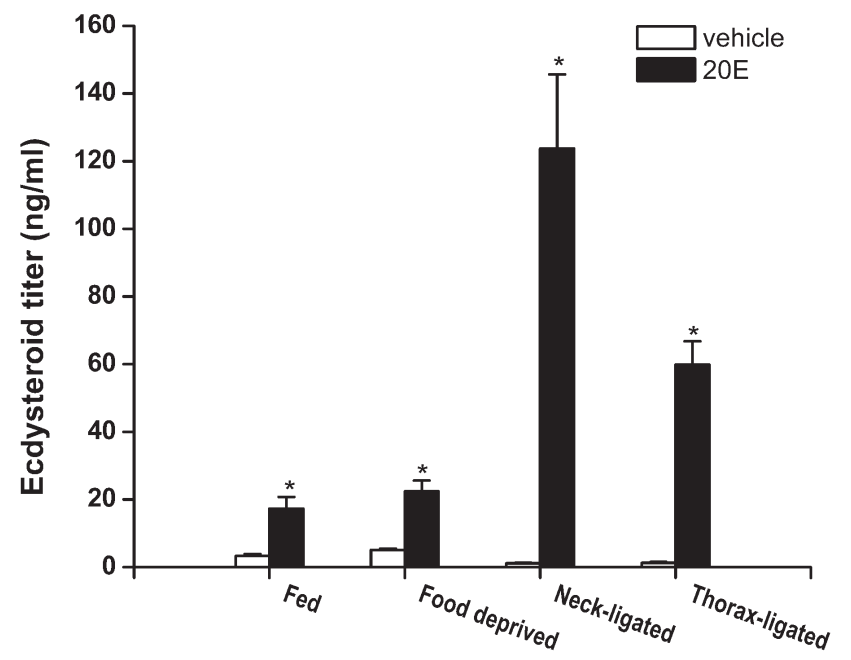

Fig. 8. The ecdysteroid titers recorded in the haemolymph of fifth instar larvae after treatment with 20-hydroxyecdysone. Graph shows the hormone level $24 \mathrm{~h}$ after the fed, food deprived and ligated larvae were treated on day 4 . Each column is the mean of 5-7 separate determinations and the error bars are the standard errors of the means (SEM). The asterisks $(*)$ indicate those that differ significantly from that recorded for the control (vehicletreated) larvae $(\mathrm{p}<0.001)$

\section{DISCUSSION}

The critical weight is the larval size at which further feeding is not necessary for normal pupation (Nijhout \& Williams, 1974b; Mirth et al., 2005; Tobler \& Nijhout, 2010). The present study showed that Bombyx larvae reach the critical weight of $2.76 \pm 0.11 \mathrm{~g}$ for metamorphosis between 3.5 and 4 days of the fifth larval instar. It was further observed that depriving them of food, beginning from day 4 , did not prevent the larvae from pupating normally. Chen \& Gu (2006) show that in B. mori food deprivation of the last larval instar from day 3 onwards results in all the larvae pupating, whereas, in the present study, food deprivation from day 3 onwards resulted in only $50 \%$ of the larvae pupating. The differences in the above findings might be because of different silkworm strains and/or laboratory rearing conditions. This study also reports an advancement in the time of pupation by almost one day, when larvae were deprived of food after attaining the critical weight (Chen \& Gu, 2006). In Drosophila, starvation post-critical weight also results in an acceleration in the rate of metamorphosis (Stieper et al., 2008; Mirth et al., 2014). On the other hand, Manduca larvae, starved post-critical weight, pupate at the same time as normally feeding control larvae (Nijhout \& Williams, 1974b; Tobler \& Nijhout, 2010). In the present study, the importance of attaining the critical weight was further confirmed by ligating larvae between the head and thorax on day 4 , as the neck-ligated larvae that survived showed prepupal behaviour, such as exposure of the dorsal vessel, gut purging and even deposition of patches of pupal cuticle. In $M$. sexta, the neck-ligation of fourth or fifth instar larvae that have attained the critical weight, does not prevent them from developing further (Safranek et al., 1980).
This study further showed that larval growth is not constant throughout the fifth instar, and is linked with the attainment of a critical weight. Although larval growth was exponential during both the phases of growth i.e. before and after attaining the critical weight, the exponent was greater during the early growth phase of the last larval instar of Bombyx. This phase of growth (pre-critical weight growth) is also essential for the larvae to undergo successful metamorphosis and is referred to here as the active growth period (AGP). The phase of growth between the attainment of the critical weight and the cessation of feeding is known as the terminal growth period (TGP) (Shingleton et al., 2007). The present study revealed a decline in larval growth rate during the TGP, as is also reported in $M$. sexta and D. melanogaster (Nijhout et al., 2006; Shingleton et al., 2008).

A low level of haemolymph ecdysteroid $(0.6-2 \mathrm{ng} / \mathrm{ml})$ was recorded in $B$. mori during the early growth phase followed by a small and sharp increase on day $4(3 \mathrm{ng} / \mathrm{ml})$. Sakurai et al. (1998) report a low haemolymph ecdysteroid level of less than $1 \mathrm{ng} / \mathrm{ml}$ in fifth instar Bombyx larvae before the head critical period (HCP) and a first significant increase $(1 \mathrm{ng} / \mathrm{ml})$ during HCP $(16 \mathrm{~h}$ on day 3 to $0 \mathrm{~h}$ on day 4). However, Gu \& Chow (1996) report a higher haemolymph ecdysteroid concentration, in the range of 3-12 ng/ $\mathrm{ml}$, in the early developmental stages of fifth instar larvae of B. mori. The daily fluctuations in ecdysteroid level, as recorded in the present study, might be due to a daily rhythm in ecdysteroid synthesis by the PTG, which is under the influence of the daily release of the PTTH (Sakurai et al., 1998). In the present study, Bombyx fifth instar larvae attained the critical weight between 3.5 and 4 days, and coincidently a small but significant peak of ecdysteroid was recorded on day 4 . Thus, the data indicate that this peak of ecdysteroid might be linked with the attainment of the critical weight by Bombyx larvae. In D. melanogaster, a small nutrition-sensitive ecdysone peak, occurs early in the third larval instar and is associated with the achievement of the critical weight by the larvae (Koyama et al., 2014). The achievement of the critical weight, in turn, can trigger the release of the PTTH for the synthesis of ecdysone and the commitment to metamorphosis (see review by Mirth \& Riddiford, 2007).

The effect of food deprivation on ecdysteroid level was dependent on the developmental phase of the fifth larval instar. An increase in ecdysteroid level was recorded only in the haemolymph of larvae deprived of food after attaining the critical weight. Since an increase in the haemolymph ecdysteroid level is primarily due to the increased secretory activity of the PTG and since the growth of the PTG in Bombyx starts during the latter phase of the fifth instar larva, it might be presumed that the PTG is responsive to nutrition only after and not before the critical weight is attained. The deprivation of food after the critical weight is attained might stimulate the NSCs of the brain to release PTTH and/or might augment the PTTH signal transduction pathway for increased ecdysteroid synthesis. Layalle et al. (2008) report that in D. melanogaster, nutrition acts 
on the PTG during a restricted time window near the end of larval development, which coincides with the commitment to pupation. Layalle et al. (2008) further reports that the Target of the rapamycin (TOR) pathway in the PTG is a core component of the nutrient-response pathway, which links nutritional inputs to ecdysone synthesis. As the deprivation of food after larvae attain the critical weight resulted in an advancement in the time of pupation by almost one day, it is believed that the increase in ecdysteroid level triggered an earlier metamorphic moult or shortened the terminal growth period of larvae of Bombyx deprived of food. Chen \& Gu (2006) report an increase in ecdysteroid level after $48 \mathrm{~h}$ of food deprivation that began on day 3 of the last larval instar of $B$. mori. The present study revealed an increase in the ecdysteroid level of larvae that had attained the critical weight 24 and $48 \mathrm{~h}$ after they were deprived of food. In Manduca larvae, however, food deprivation results in a significant decrease in the ability of the PTG to secrete ecdysone relative to that in the fed control (Walsh $\&$ Smith, 2011). The effect of food deprivation on larval developmental time and ecdysteroid level is thus different in Bombyx and Manduca larvae.

The injection of insulin into larvae provided with food resulted an increase in the level of ecdysteroid in both 1 day and 4 day old fifth instar larvae (before and after attaining the critical weight). The increase in the level of ecdysteroid following the injection of insulin might be due to increased ecdysteroidogenesis by the PTG (Gu et al., 2009; Smith et al., 2014). In vitro studies on $B$. mori have revealed that insulin causes an increase in ecdysteroidogenesis in the PTG, but only when PTGs are isolated after day 4 of last instar larvae (Gu et al., 2009). However, it should be noted in their study a short incubation period of $8 \mathrm{~h}$ was used and that might have been insufficient to stimulate insulinmediated ecdysteroidogenesis. Recently, it has been shown that ecdysteroidogenesis is stimulated by bombyxin in isolated PTGs of 7 day old last instar larvae, but only when incubated for longer (24 h) (Gu et al., 2015), though earlier studies indicate that bombyxin, at physiological doses, has no effect on ecdysteroidogenesis in B. mori (Kiriishi et al., 1992; Ishizaki \& Suzuki, 1994). It is also reported that the PTG in the early stage of the fifth instar is not even responsive to PTTH due to a deficiency in PTTH signaling (Gu et al., 1996). Although PTTH does not induce steroidogenesis in isolated PTGs during the early stages of the last larval instar (Okuda et al., 1985; Gu \& Chow, 1993; Gu et al., 1996, 1997), in intact larvae, however, a detectable level of ecdysteroid in the haemolymph is reported $(\mathrm{Gu} \&$ Chow, 1996; Sakurai et al., 1998; this study). Thus, we hypothesize that although the PTG is a likely candidate for insulin-mediated increased ecdysteroidogenesis in 1 day old Bombyx larvae provided with food, the involvement of other tissues cannot be ruled out, as in the present study an increase in ecdysteroid level was recorded in both neckand thorax-ligated day 4 larvae injected with insulin. In A. aegypti, insulin stimulates ecdysteroidogenesis in ovarian tissues (Graf et al., 1997, Riehle \& Brown, 1999). In Drosophila, insulin/IGF signaling controls the basal levels of ecdysone synthesis in the PTG and transgene manipulations of the insulin producing cells (IPCs) reveals that an increase in insulin signaling causes an increase in ecdysteroidogenesis (Colombani et al., 2005; Walkiewicz \& Stern, 2009). However, in M. sexta, insulin does not stimulate the PTG and increase ecdysone synthesis (Walsh \& Smith, 2011; Smith et al., 2014). The reason for this discrepancy in the insulin-mediated ecdysteroidogenesis by the prothoracic gland is not clear (Smith et al., 2014).

The topical application of methoprene (JHA), like insulin, also caused an increase in the ecdysteroid level, when 1 day old larvae were used. It was earlier shown that fenoxycarb (JHA) prevents the PTG from ecdysteroid synthesis and secretion in early fifth instar larvae of Bombyx (Dedos \& Fugo, 1996). It is also reported that JH acts not only indirectly through the PTTH to inhibit ecdysteroidogenesis but also exerts a direct effect on the PTG by preventing it responding to PTTH (Sakurai et al., 1989; Gu et al., 1997). A recent study indicates that treatment of newly moulted fifth instar larvae with methoprene delayed the normal decline in the PTTH receptor (Torso) gene in the PTG of $B$. mori (Young et al., 2012). Thus, the increase in the level of ecdysteroid after $\mathrm{JH}$ treatment, as recorded in the present study, might be because this treatment maintains PTG activity in terms of the functioning of the PTTH receptor. It is note-worthy that in the present study, during the normal course of development of the fifth instar larvae, 1 day old larvae had a higher level of ecdysteroid in their haemolymph than 2 day old larvae (Fig. 3) and since the JH treatment was done on day 1 and the ecdysteroid level was measured $24 \mathrm{~h}$ later, i.e. on day 2 , it might be possible that the higher level of ecdysteroid in methoprene-treated larvae compared to 2 day old fed larvae is due to a delay in the decline in its level in 1 day larvae after methoprene treatment. The possibility of the participation of other tissue/s in the increase in ecdysteroid synthesis cannot be ruled out. The gonads, such as testis and ovary, along with the epidermis and oenocytes are proposed as alternative tissues for ecdysteroid synthesis (see review by Marchal et al., 2010). In B. mori, the ovary synthesizes ecdysone, but this is only recorded for developing adults (Ohnishi \& Chatani, 1977). In A. aegypti, tissues dissected from the thorax and abdomen of fourth instar larvae to pupae also synthesize and release ecdysteroids (Jenkins et al., 1992; Telang et al., 2007). In the lepidopteran species, Heliothis virescens, Lymantria dispar, Ostrinia nubilalis, Mamestra brassicae, Leucania separate and Spodoptera littoralis, the testicular tissues at the end of the last larval instar and during pupal development also synthesize ecdysteroid (Loeb et al., 1982, 1988; Shimizu et al., 1985, 1989; Gelman et al., 1989; Jarvis et al., 1994). As in the present study, only female larvae were used, it is possible that the larval ovary can also synthesize a basal level of ecdysteroid and its synthesis is augmented after JH or insulin treatment.

In food deprived larvae, injection of insulin resulted in a developmentally regulatory effect on the level of ecdysteroid. Injection of insulin into 1 day old larvae deprived of food did not result in an increase in the level of ecdyster- 
oid, but the same treatment of 4 day old larvae deprived of food did. Based on the results of the present study, it seems that for 4 day old larvae the increase in the level in ecdysteroid is due to an association between the critical weight and the sensitivity to insulin, as in Drosophila, ecdysone synthesis requires both attainment of a specific body size and its production at the appropriate circadian time, which is regulated by both insulin and PTTH via PI3K and Ras pathways (Walkiewicz \& Stern, 2009). These two pathways, acting together, activate the transcription of the PTG specific "Halloween genes", which encode the ecdysone biosynthetic enzymes, ultimately triggering ecdysone synthesis. Like insulin, JH treatment also failed to increase the level of ecdysteroid in 1 day old larvae deprived of food (before attaining the critical weight). The failure of both $\mathrm{JH}$ and insulin to increase the level of ecdysteroid in larvae deprived of food during their active growth phase might be because of the absence of nutritional inputs as both these hormones are known to have growth promoting effects. The increase in ecdysteroidogenesis recorded in larvae that had attained the critical weight and were then deprived of food and injected with insulin might be due to an alteration in the competency of the PTG and/or other tissues to insulin associated with attaining the critical weight. Sakurai et al. (1998) report that the responsiveness of the PTG to PTTH is higher in larvae that are deprived of food after HCP, than those of larvae deprived of food before HCP. Tobler \& Nijhout (2010) indicate that it is likely that the expression of insulin is decoupled from nutrition after Manduca larvae attain the critical weight. In our study, after attaining the critical weight, although larvae deprived of food had a higher level of ecdysteroid than fed larvae, but after injection with insulin, the fold-increase in fed and food deprived larvae were almost same with vehicle-treated fed and food deprived larvae respectively. As after the critical weight was attained, injection with insulin caused an increase in the level of ecdysteroid in both fed and food deprived larvae, and before critical weight was attained, injection of insulin caused an increase in the level ecdysteroid only in fed larvae, it is likely that the action of insulin on ecdysteroidogenesis is related to feeding, but only before the critical weight is attained. The present study revealed that the effect of insulin is dependent not only on the nutritional status but also the stage of development of a fifth instar larva.

Neck- and thorax-ligated 4 day old fifth instar larvae, as expected, had a significantly lower level of ecdysteroid in their haemolymph $24 \mathrm{~h}$ after ligation ( 5 day old) than normal 5 day old larvae. Careful examination revealed that the level of ecdysteroid in ligated larvae $(1 \mathrm{ng} / \mathrm{ml})$ was almost at the same as that recorded in normal larvae for day 4 at $6 \mathrm{~h}$. This indicates that in ligated larvae as the source of PTTH was removed, further ecdysteroidogenesis in the PTG was prevented, possibly because of the absence of a second release of PTTH, which might normally occur between 6-12 $\mathrm{h}$ on day 4 , that is, after ligation, as revealed by the normal developmental profile (Fig. 3). The injection of insulin into neck- and thorax-ligated larvae (after attaining the critical weight), however, resulted in a significant increase in the level of ecdysteroid in both cases, although the increase was greater in neck-ligated than thorax-ligated larvae. The data thus strongly indicates that although insulin acted on prothoracic gland and increased ecdysteroid synthesis, at the same time, it might also have interacted with other tissues in the abdomen, which also resulted in an increase in ecdysteroid synthesis, as evident from the increased level of ecdysteroid following the injection of thorax-ligated larvae with insulin. Petryk et al. (2003) show that the Halloween enzyme Shade is required for converting ecdysone into 20-hydroxyecdysone (active ecdysteroid) in the peripheral tissues but not in the prothoracic gland.

The increase in the level of ecdysteroid in haemolymph after $20 \mathrm{E}$ treatment varied depending on the experimental conditions. The level of ecdysteroid increased, but almost to the same level in both 20E-treated fed and food deprived larvae. However, 20E-neck-ligated larvae showed a greater increase than the corresponding 20E-treated fed and food deprived larvae. Likewise, a greater increase was recorded in thorax-ligated larvae, although less than that recorded in neck-ligated larvae. At present, it is difficult to account for these results, but it likely that both the brain and PTG are involved in regulating the catabolism of exogenous ecdysteroid. A feedback mechanism operating through the NSCs in the brain or through the PTG regulating the level of ecdysteroid, however, also cannot be ruled out.

In conclusion, the present study clearly indicates that during the feeding phase of the fifth larval instar of the silkworm, B. mori, the level of haemolymph ecdysteroid is highly dependent on the nutritional status and phase of development (critical weight) of the larvae.

ACKNOWLEDGEMENTS. This study was supported by grant BT/PR14289/BRB/10/837/2010 (2011-2014) from the Department of Biotechnology (DBT) under Basic Research and Emerging Areas, Government of India. We thank the Director, Central Sericultural Germplasm Resource Centre (CSGRC), CSB, Hosur, Tamil Nadu, India, for providing us disease-free silkworm layings (dfls) and the anonymous reviewers for critical and helpful comments that improved this manuscript. We are also grateful to N.V. Singh, Department of Statistics, NEHU, for helping us with the use of R software.

\section{REFERENCES}

Bollenbacher W.E. \& Granger N.A. 1985: Endocrinology of the prothoracicotropic hormone. In Kerkut G.A. \& Gilbert L.I. (eds): Comprehensive Insect Physiology, Biochemistry and Pharmacology. Vol. 7. Pergamon, Oxford, UK, pp. 109-151.

Caldwell P.E., Walkiewicz M. \& Stern M. 2005: Ras activity in the Drosophila prothoracic gland regulates body size and developmental rate via ecdysone release. - Curr. Biol. 15: 1785-1795.

CHen C.H. \& Gu S.H. 2006: Stage-dependent effects of food deprivation on the growth, metamorphosis, and ecdysteroidogenesis by the prothoracic glands during the last larval instar of the silkworm, Bombyx mori. - J. Insect Physiol. 52: 968-974.

Colombani J., Bianchini L., Layalle S., Pondeville E., Dauphin-Villemant C., Antoniewsiki C., Carre C., Noselli S. \& LÉOPOLD P. 2005: Antagonistic actions of ecdysone and insulin determine final size in Drosophila. - Science 310: 667-670. 
Dedos S.G. \& Fugo H. 1996: Effects of fenoxycarb on the secretory activity of the prothoracic glands in the fifth instar of the silkworm, Bombyx mori. — Gen. Comp. Endocrinol. 104: 213-224.

Dubrovsky E.B. 2005: Hormonal cross talk in insect development. - Trends Endocrinol. Metab. 16: 6-11.

Gelman D.B., Woods C.W., Loeb M.J. \& Borkovec A.B. 1989: Ecdysteroid synthesis by testes of 5th instars and pupae of the European corn borer, Ostrinia nubilalis (Hubner). - Invert. Reprod. Dev. 15: 177-184.

Gilbert L.I., RybCZYNSKi R. \& WarRen J.T. 2002: Control and biochemical nature of the ecdysteroidogenic pathway. - Annu. Rev. Entomol. 47: 883-916.

Gillott C. \& Ismail P.M. 1995: In vitro synthesis of ecdysteroid by the male accessory reproductive glands, testis and abdominal integument of the adult migratory grasshopper, Melanoplus sanguinipes. - Invert. Reprod. Dev. 27: 65-71.

Graf R., Neuenschwander S., Brown M.R. \& Ackermann U. 1997: Insulin mediated secretion of ecdysteroids from mosquito ovaries and molecular cloning of the insulin receptor homologue (MIR) from ovaries of blood fed Aedes aegypti. - Insect Mol. Biol. 6: 151-163.

Gu S.H. 2007: Autocrine activation of ecdysteroidogenesis in prothoracic glands of the silkworm, Bombyx mori. - J. Insect Physiol. 53: 538-549.

Gu S.H. \& Chоw Y.S. 1993: Role of low ecdysteroid levels in the early last larval instar of Bombyx mori. - Experientia 49: 806-808.

Gu S.H. \& CHоw Y.S. 1996: Regulation of juvenile hormone biosynthesis by ecdysteroid levels during the early stages of the last two larval instars of Bombyx mori. - J. Insect Physiol. 42: 625-632.

Gu S.H., Chow Y.S., Lin F.J., Wu J.L. \& Ho R.J. 1996: A deficiency in prothoracicotropic hormone transduction pathway during the early last larval instar of Bombyx mori. - Mol. Cell. Endocrinol. 120: 99-105.

Gu S.H. Chоw Y.S. \& YIN C.M. 1997: Involvement of juvenile hormone in regulation of prothoracicotropic hormone transduction during the early last larval instar of Bombyx mori. Mol. Cell. Endocrinol. 127: 109-116.

Gu S.H., Lin J.L., Lin P.L. \& CHEN C.H. 2009: Insulin stimulates ecdysteroidogenesis by prothoracic glands in the silkworm, Bombyx mori. - Insect Biochem. Mol. Biol. 39: 171-179.

Gu S.H., Chen C.H., Hsien Y.C., Lin P.L. \& Young S.C. 2015: Modulatory effects of Bombyx in on ecdysteroidogenesis in Bombyx mori prothoracic glands. - J. Insect Physiol. 72: $61-69$.

Hentze J.L., Moeller M.E., Jorgensen A.F., Bengtsson M.S., Bordoy A.M., Warren J.T., Gilbert L.I., Andersen O. \& ReWITZ K.F. 2013: Accessory gland as a site for prothoracicotropic hormone controlled ecdysone synthesis in adult male insects. - PLOS ONE 8: e55131.

IHAKA R. \& GENTLEMAn R. 1996: R: A language for data analysis and graphics. - J. Comput. Graph. Stat. 5: 299-314.

IsHIZAKI H. \& SUzUKI A. 1994: The brain secretory peptides that control moulting and metamorphosis of the silkworm, Bombyx mori. - Int. J. Dev. Biol. 38: 301-310.

Jarvis T.D., EARLey F.G.P. \& ReEs H.H. 1994: Ecdysteroid biosynthesis in larval testes of Spodoptera littoralis. - Insect Biochem. Mol. Biol. 24: 531-537.

JenkINS S.P., BRown M.R. \& LEA A.O. 1992: Inactive prothoracic glands in larvae and pupae of Aedes aegypti: ecdysteroid release by tissues in the thorax and abdomen. - Insect Biochem. Mol. Biol. 22: 553-559.
Kirishi S., Nagasama H., Kataoka H., Suzuki A. \& Sakurai S. 1992: Comparison of the in vivo and in vitro effects of bombyxin and prothoracicotropic hormone on prothoracic glands of the silkworm, Bombyx mori. - Zool. Sci. 9: 149-155.

Koyama T., Rodrigues M.A., Athanasiadis A., Shingleton A.W. \& MiRTH C.K. 2014: Nutritional control of body size through FoxO-Ultraspiracle mediated ecdysone biosynthesis. - eLife 3: e03091.

Layalle S., Arquier N. \& Léopold P. 2008: The TOR pathway couples nutrition and developmental timing in Drosophila. Dev. Cell 15: 568-577.

Loeb M.J., Brandt E.P., Woods C.W. \& Bell R.A. 1988: Secretion of ecdysteroid by sheaths of testes of the gypsy moth, Lymantria dispar, and its regulation by testis ecdysiotropin. J. Exp. Zool. 248: 94-100.

Loeb M.J., Woods C.W., Brandt E.P. \& Borkovec A.B. 1982: Larval testes of the tobacco budworm: a new source of insect ecdysteroids. - Science 218: 896-898.

Maniere G., Rondot I., Bullesbach E.E., Gautron F., Vanhems E. \& DelbecQue J.P. 2004: Control of ovarian steroidogenesis by insulin-like peptides in the blowfly (Phormia regina). $-J$. Endocrinol. 181: 147-156.

Marchal E., Vandersmissen H.P., Badisco L., Van de Velde S. Verlinden H., Iga M., Van Wielendaele P., Huybrechts R., Simonet G., Smagghe G. \& Broeck J.V. 2010: Control of ecdysteroidogenesis in prothoracic glands of insects: A review. - Peptides 31: 506-519.

MirTh C.K. \& RidDIFORD L.M. 2007: Size assessment and growth control: how adult size is determined in insects. - BioEssays 29: $344-355$.

Mirth C.K. \& Shingleton A.W. 2012: Integrating body and organ size in Drosophila: recent advances and outstanding problems. —Front. Endocrinol. 3: 49.

Mirth C., Truman J.W. \& Riddiford L.M. 2005: The role of the prothoracic gland in determining critical weight for metamorphosis in Drosophila melanogaster. - Curr. Biol. 15: 17961807.

Mirth C.K., Tang H.Y., Makohon-Moore S.C., Salhadar S., Gokhale R.H., Warner R.D., Koyama T., Riddiford L.M. \& SHINGLETON A.W. 2014: Juvenile hormone regulates body size and perturbs insulin signaling in Drosophila. - Proc. Natl. Acad. Sci. USA 111: 7018-7023.

Nishout H.F. 2003: The control of body size in insects. - Dev. Biol. 261: 1-9.

Nishout H.F. \& Williams C.M. 1974a: Control of moulting and metamorphosis in the tobacco hornworm, Manduca sexta (L.): cessation of juvenile hormone secretion as a trigger for pupation. - J. Exp. Biol. 61: 493-501.

Nishout H.F. \& Williams C.M. 1974b: Control of moulting and metamorphosis in the tobacco hornworm, Manduca sexta (L.): growth of the last-instar larva and the decision to pupate. - J. Exp. Biol. 61: 481-491.

Nishout H.F., Davidowitz G. \& RofF D.A. 2006: A quantitative analysis of the mechanism that controls body size in Manduca sexta. - J. Biol. 5: 16

Nijhout H.F., Riddiford L.M., Mirth C., Shingleton A.W., SuZUKI Y. \& CALLIER V. 2014: The developmental control of size in insects. - WIREs Dev. Biol. 3: 113-134.

OHNishi E. \& Chatani F. 1977: Biosynthesis of ecdysone in the isolated abdomen of the silkworm, Bombyx mori. - Dev. Growth Differ. 19: 67-70.

OKUDA M., SAKURAI S. \& OHTAKI T. 1985: Activity of the prothoracic gland and its sensitivity to prothoracicotropic hormone in the penultimate and last-larval instar of Bombyx mori. - J. Insect Physiol. 31: 455-461. 
Petryk A., Warren J.T., Marques G., Jarcho M.P., Gilbert L.I., Kahler J., Parvy J.P., Li Y.T., Dauphin-Villemant C. \& O'Connor M.B. 2003: Shade is the Drosophila P450 enzyme that mediates the hydroxylation of ecdysone to the steroid insect molting hormone 20-hydroxyecdysone. - Proc. Natl. Acad. Sci. USA 100: 13773-13778.

Porcheron P., Moriniere M., Grassi J. \& Pradelles P. 1989: Development of an enzyme immunoassay for ecdysteroids using acetylcholinesterase as label. — Insect Biochem. 19: 117-122.

RIDDIFORD L.M. 1994: Cellular and molecular actions of juvenile hormone: I. General considerations and premetamorphic actions. - Adv. Insect Physiol. 24: 213-274.

Riddiford L.M., Hiruma K., Zhou X. \& Nelson C.A. 2003: Insights into the molecular basis of the hormonal control of molting and metamorphosis from Manduca sexta and Drosophila melanogaster. - Insect Biochem. Mol. Biol. 33: 1327-1338.

RieHLE M.A. \& BRown M.R. 1999: Insulin stimulates ecdysteroid production through a conserved signaling cascade in the mosquito Aedes aegypti. - Insect Biochem. Mol. Biol. 29: $855-860$.

RYBCZYNSKI R. 2005: Prothoracicotropic hormone. In Gilbert L.I., Iatrou K. \& Gill S. (eds): Comprehensive Molecular Insect Science. Vol. 3. Elsevier, Amsterdam, pp. 61-123.

Safranek L., Cymborowski B. \& Williams C.M. 1980: Effects of juvenile hormone on ecdysone-dependent development in the tobacco hornworm, Manduca sexta. - Biol. Bull. 158: $248-256$.

Sakurai S., Kaya M. \& Satake S. 1998: Hemolymph ecdysteroid level and ecdysteroid-dependent developmental events in the last-larval stadium of the silkworm, Bombyx mori: role of low ecdysteroid level in larval-pupal metamorphosis and a reappraisal of the head critical period. - J. Insect Physiol. 44: 867-881.

Sakurai S., OKuda M. \& Ohtaki T. 1989: Juvenile hormone inhibits ecdysone secretion and responsiveness to prothoracicotropic hormone in prothoracic glands of Bombyx mori. - Gen. Comp. Endocrinol. 75: 222-230.

Shimada-Niwa Y. \& Niwa R. 2014: Serotonergic neurons respond to nutrients and regulate the timing of steroid hormone biosynthesis in Drosophila. - Nat. Commun. 5: 5778.

Shimizu T., Moribayashi A. \& Agui N. 1985: In vitro analysis of spermiogenesis and testicular ecdysteroids in the cabbage army worm, Mamestra brassicae L. - Appl. Entomol. Zool. 20: $56-61$.

Shimizu T., Yagi S. \& Agui N. 1989: The relationship of testicular and hemolymph ecdysteroid level to spermiogenesis in the common armyworm, Leucania separata. - Entomol. Exp. Appl. 50: 195-198.
Shingleton A.W., Das J., Vinicius L. \& Stern D.L. 2005: The temporal requirements for insulin signaling during development in Drosophila. - PLOS Biol. 3: e289.

Shingleton A.W., Mirth C.K. \& Bates P.W. 2008: Developmental model of static allometry in holometabolous insects. Proc. R. Soc. (B) 275: 1875-1885.

Smith W.A., Lamattina A. \& Collins M. 2014: Insulin signaling pathways in lepidopteran ecdysone secretion. - Front. Physiol. 5: 1-8.

Stieper B.C., Kupershtok M., Driscoll M.V. \& Shingleton A.W. 2008: Imaginal discs regulate developmental timing in Drosophila melanogaster. - Dev. Biol. 321: 18-26.

TANAKA Y. 2011: Recent topics on the regulatory mechanism of ecdysteroidogenesis by the prothoracic gland in insects. Front. Endocrinol. 107: 1-6.

Telang A., Frame L. \& Brown M.R. 2007: Larval feeding duration affects ecdysteroid levels and nutritional reserves regulating pupal commitment in the yellow fever mosquito Aedes aegypti (Diptera: Culicidae). - J. Exp. Biol. 210: 854-864.

Tobler A. \& Nijhout H.F. 2010: A switch in the control of growth of the wing imaginal disks of Manduca sexta. - PLoS ONE 5: e10723.

TRUMAN J.W. 2006: Steroid hormone secretion in insects comes of age. - Proc. Natl. Acad. Sci. USA 103: 8909-8910.

TRUMAn J.W. \& RidDiford L.M. 2007: The morphostatic actions of juvenile hormone. - Insect Biochem. Mol. Biol. 37: 761770.

Vafopoulou X. \& Steel C.G.H. 1997: Ecdysteroidogenic action of Bombyx prothoracicotropic hormone and Bombyx in on the prothoracic glands of Rhodnius prolixus in vitro. - J. Insect Physiol. 43: 651-656.

Walkiewicz M.A. \& Stern M. 2009: Increased insulin/insulin growth factor signaling advances the onset of metamorphosis in Drosophila. - PLoS ONE 4: e5072.

Walsh A.M. \& Sмiтh W.A. 2011: Nutritional sensitivity of fifth instar prothoracic glands in the tobacco hornworm, Manduca sexta. - J. Insect Physiol. 57: 809-818.

Yamanaka N., Hua Y.J., Mizoguchi A., Watanabe K., Niwa R., TANAKA Y. \& KatAOKA H. 2005: Identification of a novel prothoracicostatic hormone and its receptor in the silkworm Bombyx mori. - J. Biol. Chem. 280: 14684-14690.

Young S.C., YeH W.L. \& Gu S.H. 2012: Transcriptional regulation of PTTH receptor in prothoracic glands of the silkworm, Bombyx mori. - J. Insect Physiol. 58: 102-109.

Received December 3, 2014; revised and accepted June 24, 2015 Prepublished online August 27, 2015 